\title{
Major Causes of Organs and Carcass Condemnation and Financial Losses in Cattle Slaughtered at Adama Municipal Abattoir, Adama, Ethiopia
}

\author{
Bedaso Kebede ${ }^{1,2, *}$, Mekdes Abay ${ }^{3}$, Teshome Gunse ${ }^{4}$ \\ ${ }^{1}$ Animal Products, Veterinary Drug and Animal Feed Quality Assessment Center, Veterinary Drug and Animal Feed Administration and \\ Control Authority, Addis Ababa, Ethiopia \\ ${ }^{2}$ Department of Pharmacology, School of Pharmacy, College of Health Science, Addis Ababa University, Addis Ababa, Ethiopia \\ ${ }^{3}$ Veterinary Drug and Animal Feed, Inspection Directorate, Veterinary Drug and Animal Feed Administration and Control Authority, Addis \\ Ababa, Ethiopia \\ ${ }^{4}$ Field Veterinarian, Livestock and Fisheries Development of Sire District Office, Arsi Zone, Oromia Region, Ethiopia
}

Email address:

Kebede.bedaso@yahoo.com (B. Kebede), Mekdesabay21@gmail.com (M. Abay), mataniya3366@gmail.com (T. Gunse)

${ }^{*}$ Corresponding author

\section{To cite this article:}

Bedaso Kebede, Mekdes Abay, Teshome Gunse. Major Causes of Organs and Carcass Condemnation and Financial Losses in Cattle Slaughtered at Adama Municipal Abattoir, Adama, Ethiopia. International Journal of Economic Behavior and Organization.

Vol. 8, No. 2, 2020, pp. 31-37. doi: 10.11648/j.ijebo.20200802.12

Received: December 2, 2019; Accepted: December 24, 2019; Published: May 18, 2020

\begin{abstract}
Abattoirs play an important role in examining signs, lesions or specific diseases of surveillance of various diseases that have human and animal health importance. Surveillance at the abattoir allows for all animals passing into the human food chain to be inspected. Monitoring and other conditions at slaughter have been recognized as one way of assessing the disease status of the herd. Abattoir data can be a source of valuable information on the incidence and epidemiology of animal disease conditions, to estimate the financial losses incurred through the condemnation of affected organs. The study was conducted from November 2016 to April 2017 in Adama municipal abattoir, at Adama. The aim of this study was to identify the significant causes of organ condemnation and to estimate the magnitude of the direct financial losses attributed to the condemned organs from cattle slaughtered in the abattoir. Standard antemortem and postmortem inspection procedures were followed throughout the study. The antemortem inspection was carried out on arrival and in the lairage and abnormalities encountered was recorded, followed by postmortem examination through their identification number to detect gross abnormalities and aesthetic reasons that rendered each organ to be rejected from the domestic market. The estimation of financial losses is based on the annual slaughter capacity of the abattoir and considering the market average price of each organ. The study revealed that from a total of 384 slaughtered animals $63(16.40 \%)$ were found to have signs of detectable abnormalities in the antemortem inspection. The clinical signs observed during an antemortem inspection from 63 animals were depression (5.46\%), nasal discharge (4.68\%), coughing (2.46\%), lameness (1.56\%) and local swelling ().18\%). However, during postmortem inspection offal organs of slaughtered animals shown lesions and subjected to condemnation were liver $(62.76 \%)$, lung $(59.37 \%)$, and heart $(9.37 \%)$. The identified microorganisms responsible for the condemnation of these organs in the study were fasciolosis $(30.46 \%)$, hydatidosis $(32.29 \%)$ and pericarditis $(5.73 \%)$. The condemnation of this much organs resulted in a financial loss estimated to be 3,533,428.50 (ETB) or 152,763.862 USD annually. This study implies that high prevalence organ condemnation, particularly by parasitic infections. This warranties that awareness creation to animal owners on its animal husbandry management and animal health control measures like regular deworming.
\end{abstract}

Keywords: Adama Abattoir, Cattle, Financial Loss, Antemortem, Postmortem, Inspection 


\section{Introduction}

Livestock resource utilization was driven because of several factors such as population growth, increases in the demand for livestock products as incomes rise, and urbanization [1]. Livestock production at this moment covers about $30 \%$ of the agricultural gross domestic product in developing countries that could be projected to increase about $40 \%$ by 2030 and is becoming the fastest growing subsector of agriculture [2]. Livestock is an important component of nearly all farming systems in Ethiopia and provides draught, power, milk, meat, manure, hides, skins and other products [3]. Currently, the population of livestock found in Ethiopia is estimated to be 53.4 million cattle, 25.5 million sheep and 22.78 million goats [4].

The cattle in Ethiopia are well adapted to the tropical environment producing and reproducing under stress of high degree of temperature, high disease prevalence and low level of nutritional states [22]. Hence, an increase in cattle production could contribute to the attainment of food self-sufficiency in the country particularly in response to protein requirement for the growing human population as well as to enhance the export earnings [12]. Ethiopia's largest livestock population has been contributing a considerable portion to the economy of the country, and still promising for the economic development of the country. It is eminent that livestock products and by-products in the form of meat, milk, cheese, and butter provide the needed animal protein that contributes to the improvement of the nutritional status of the people. Among livestock, cattle also play an important role in providing export commodities, such as live animals, meat and hides to earn foreign exchanges to the country [10].

Abattoirs play an important role in examining signs, lesions or specific diseases of surveillance of various diseases that have human and animal health importance. Surveillance at the abattoir allows for all animals passing into the human food chain to be inspected [7; 4]. Monitoring and other conditions at slaughter have been recognized as one way of assessing the disease status of the herd, however, this source of information is not fully exploited worldwide [20]. Abattoir data is an excellent option for detecting diseases of both economic and public health significance [2]. Abattoir data can be a source of valuable information on the incidence and epidemiology of animal disease conditions, to estimate the financial losses incurred through the condemnation of affected organs [25]. An important function of meat inspection is to assist in monitoring diseases in the national herd and flock by providing feedback information to the veterinary service to control or eradicate diseases [15].

The main causes of organ condemnation during post mortem inspection are diseases originated by parasites, bacteria, and viruses. Flukes in the liver and hydatid cyst in the lung, liver, and heart, are mainly involved [21]. Parasites in the tropics are responsible for the far greater loss to the meat industry than any other disease [17]. Similarly, like many other tropical countries in Africa, it is well known that parasitic diseases are the major factors responsible for the low productivity of livestock in Ethiopia [17; 1]. In Ethiopia, many studies have been undertaken to identify the major disease conditions encountered during antemortem and postmortem inspection and to determine the economic importance of organ and carcass condemnation [16]. However, no information about the causes of organ condemnation and financial losses in the current study area. Therefore, the objective of this study is to identify major causes of organ condemnations and estimate the financial losses of condemned organs of slaughtered animals at Adama municipal abattoir.

\section{Materials and Methods}

\subsection{Description of the Study Area}

Adama municipal abattoir is located at Boku Shenan kebele on the main road of Adama-Wanji road in Adama, Oromia Regional State. Adama is located at $8^{0} \mathrm{~N}$ and $39^{\circ} \mathrm{E}$. It is $99 \mathrm{~km}$ South East of Addis Ababa, the capital city of Ethiopia. The altitude is about $1700 \mathrm{~m}$ above sea level. It experiences bimodal patterns of Rainfall with the main rainy season extending from June to September with an average rainfall of about $840 \mathrm{~mm}$. The mean annual minimum and maximum temperatures are $13^{\circ} \mathrm{C}$ and $29^{\circ} \mathrm{C}$, respectively with an overall average of $18.7^{\circ} \mathrm{C}$ [9]. The mean relative humidity is $61.3 \%$.

\subsection{Study Population}

Cattle brought to the abattoir were the target for the study. Daily the abattoir visited by an average of 125 cattle of their origins were from Arsi, Bale, Kerayu, and Hararghe which include both local and crossbreeds that are managed under the traditional husbandry system.

\subsection{Study Design}

A cross-sectional study was conducted from November 2016 to April 2017 to identify the major causes of organ condemnation and estimate of financial losses of cattle slaughtered at Adama municipal abattoir. Study animals were selected using systemic random sampling for antemortem and postmortem inspection. The result of the presence or absence of lesion and the type of lesion on visible organs were recorded on the datasheet.

\subsection{Sample Size Determination}

The required sample size was calculated based on the expected prevalence of $50 \%$, absolute desired precision of $5 \%$ and at the confidence level of $95 \%$ according to the formula provided by Thrusfield [29] as follows:

$$
\mathrm{n}=\frac{1.96^{2} \mathrm{P} \exp (1-\mathrm{Pexp})}{d^{2}}
$$


Where, $\mathrm{p}=$ Expected prevalence

$\mathrm{d}=$ Absolute precision

$\mathrm{n}=$ Sample size.

$1.96=$ the value of $\mathrm{p}$

Hence, the required sample size is 384 cattle.

\subsection{Antemortem}

During the antemortem inspection, each of the study animals was examined. Sex, origin and body condition scoring of animals were recorded. Both sides of the animal were inspected at rest and in motion. Moreover, the general behavior of the animal and signs of disease were properly registered. Judgment was done according to the procedure given by [11].

\subsection{Postmortem Inspection}

During postmortem inspection offal organs such as liver, lung, and heart were thoroughly inspected by visualization, palpation, and incisions to find out for the presence of cyst, parasite and other abnormalities. Pathological lesions were differentiated and judged according to guidelines on meat inspection for developing countries and classified into the following categories of judgment: Approved as fit for human consumption, conditionally approved as fit for human consumption, totally condemned as unfit for human consumption and partially condemned as unfit for human consumption [14].

\subsection{Assessment of Financial Loss}

The estimation of financial losses due to organ condemnation was based on the annual slaughter capacity of the abattoir, considering the market condition, the average price of each organ in Adama town and the rejection rate of each organ. The annual economic loss due to major causes of organ condemnation in cattle slaughtered at Adama municipal abattoir was estimated by considering the main cost of the intended organs [26]. The market prices of organs in Adama town were obtained from abattoir workers and butchers. According to the information collected at the time of the study, the price of the liver, lung, and heart is $100 \mathrm{ETB}, 20 \mathrm{ETB}$, and $30 \mathrm{ETB}$, respectively. These parameters were then fed to the formula below in order to compute the annual financial loss due organs considered as unfit for human consumption, as a consequence of gross pathological lesions [30].

Thus,

$\mathrm{EL}=\mathrm{SSrx} * \mathrm{Coy}^{*} \mathrm{Roz}$

Where,

a) EL - Estimated annual economic loss due to organ/carcass condemnation from international/domestic market,

b) Srx - Annual cattle slaughter rate of the abattoir,

c) Coy - Average cost of each liver/lung/heart/carcass,

d) Roz - Condemnation rates of liver/lung/heart/carcass

\subsection{Data Management and Analysis}

Data generated from antemortem examination and postmortem meat inspection were entered into Microsoft excel and summarized by descriptive statistical methods. Furthermore, charts were generated from Microsoft excel to explain the results in an illustrative way. The rejection rate and the annual financial loss been calculated manually with the above-mentioned formula.

\section{Results}

\subsection{Antemortem Examination}

Out of the total of 384 cattle examined at antemortem 63 $(16.38 \%)$ cattle were found to have the abnormalities. The most common abnormalities encountered during the antemortem examination were depression (5.46\%), nasal discharge (4.68\%), coughing $(2.86 \%)$, lameness $(1.56 \%)$ and local swelling $(0.18 \%)$ (Table 1$)$.

Table 1. Abnormal conditions recorded during antemortem examination.

\begin{tabular}{lll}
\hline Abnormality & No. of cattle affected & Percentage $(\mathbf{n}=\mathbf{3 8 4})$ \\
\hline Nasal discharge & 18 & 4.68 \\
Local swelling & 7 & 0.18 \\
Coughing & 11 & 2.86 \\
Lameness & 6 & 1.56 \\
Depression & 21 & 5.46 \\
Total & 63 & 16.40 \\
\hline
\end{tabular}

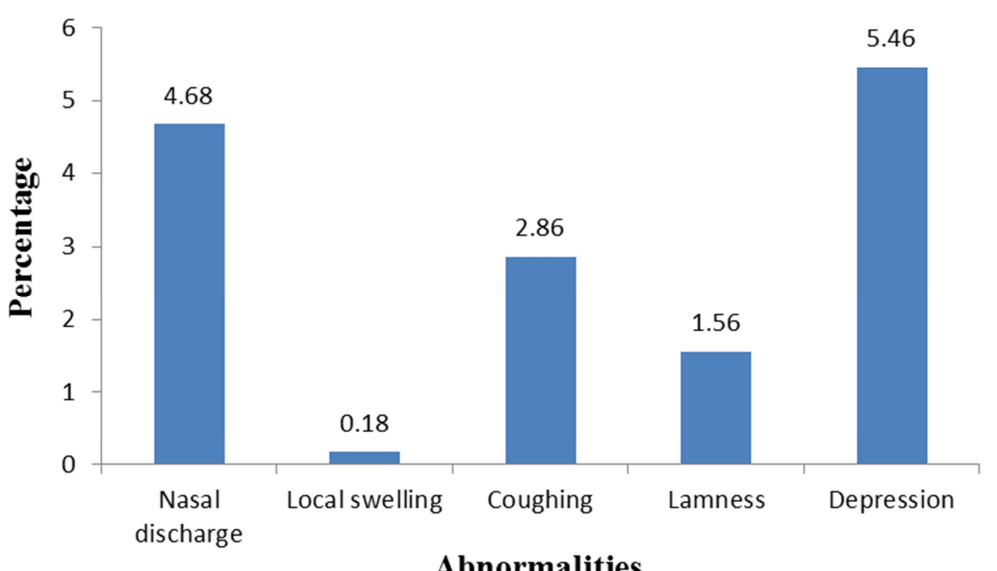

Abnormalities

Figure 1. Percentage of each of the abnormalities encountered during the antemortem examination period. 


\subsection{Postmortem Examination}

Out of 384 cattle slaughtered in Adama municipal abattoir, liver $(62.76 \%)$, lung $(59.37 \%)$, and heart $(9.37 \%)$ were totally condemned due to lesions. This study revealed that the proportion of liver condemnation percentage due to fasciolosis is the highest at $30.46 \%$ and an abscess is the least cause at
$2.34 \%$ (Figure 2). The main cause for lung condemnation in Adama municipal abattoir is hydatidosis at $32.29 \%$ and the least reason is hepatization (Figure 3) whereas in the case of heart condemnation, pericarditis takes the highest portion $(5.73 \%)$ and edema and hemorrhage showed the lowest level of condemnation rate each of them showing $1.82 \%$ (Figure 4 ).

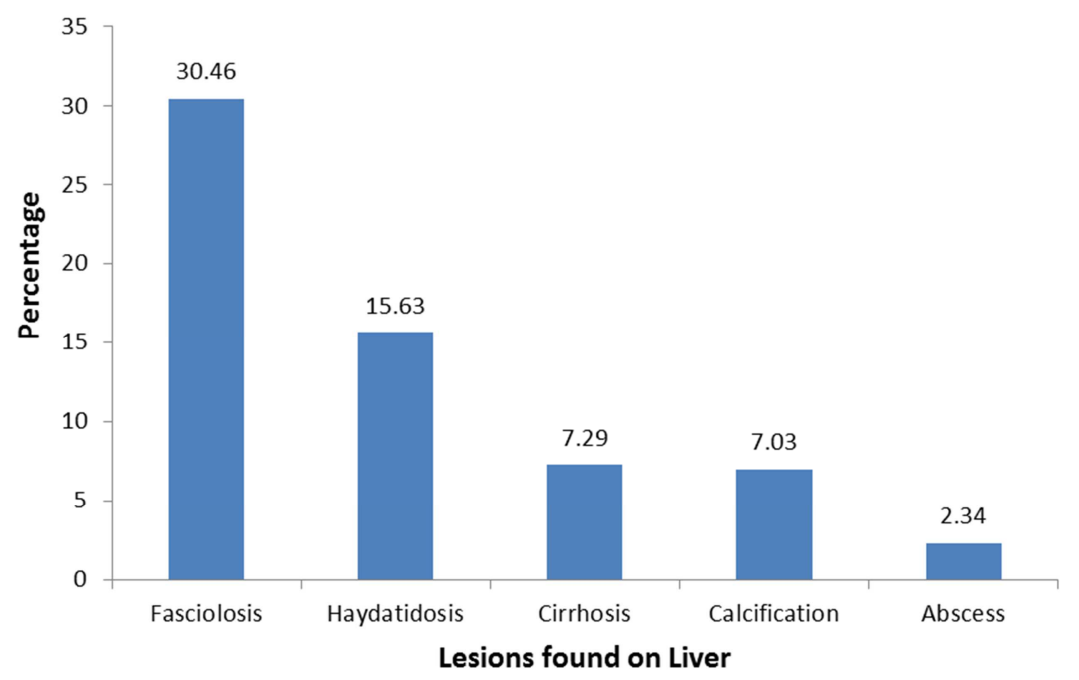

Figure 2. Percentage of each lesion found on the liver and resulted in the organ's condemnation.

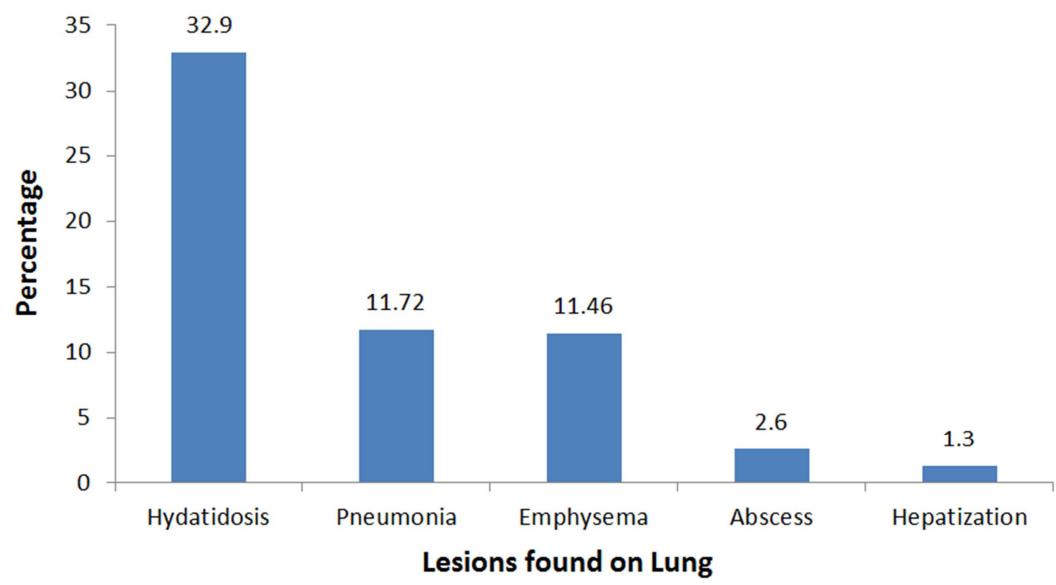

Figure 3. Percentage of each lesion found on lung and resulted in the organ's condemnation.

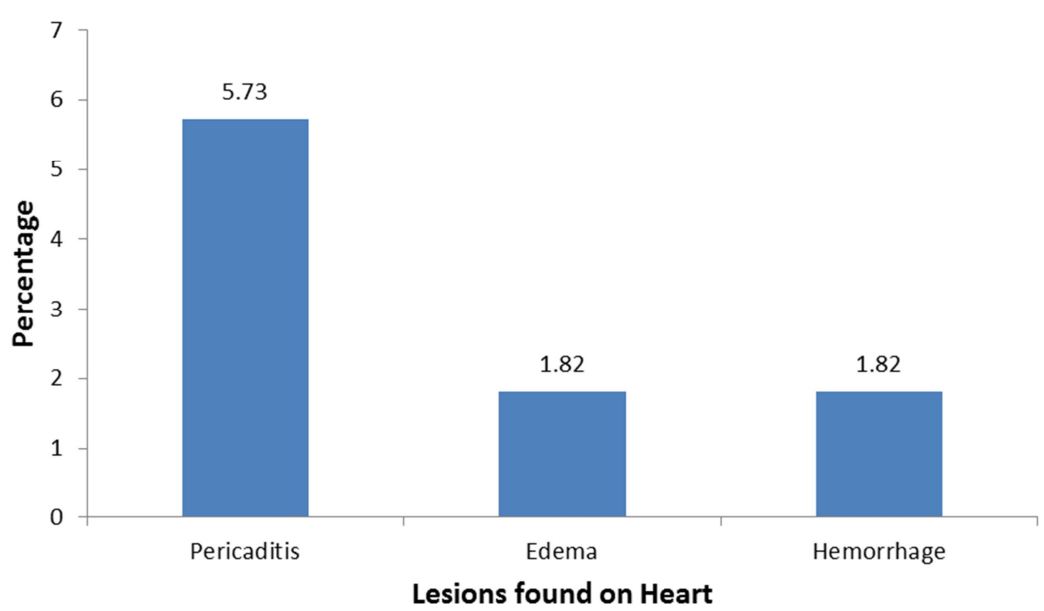

Figure 4. Percentage of each lesion found on the heart and resulted in the organ's condemnation. 


\subsection{Estimation of Financial Loss}

All animals that had been examined by the antemortem inspection were subjected to postmortem examination. From the total organs examined, 241 livers, 228 lungs, and 36 hearts were totally condemned or rejected due to gross abnormalities as unfit for human consumption. This finding indicated that the total rate of organ condemnation is 0.63 , 0.59 and 0.09 for liver, lung, and heart respectively (Table 2). Based on the data gathered from Adama municipal abattoir, the annual cattle slaughter rate of the abattoir was estimated to be 45,625 . Consequently, the annual financial loss due to rejection of the organs was calculated based on the current market prices of respective organs in Adama town were obtained from abattoir workers and butchers' shop (Table 3). The annual financial loss of liver, lung and heart condemnation was estimated to be 2,874,375 ETB, 538,375 ETB and 123,187.50 respectively. According to the result from this research, the total annual direct loss incurred due to condemnation of liver, lung and heart is estimated to be $3,535,937.50$ ETB which is equivalent to $153,736.41 \mathrm{USD}$ $(\$ 1 \mathrm{USD}=23.13 \mathrm{ETB})$ using the formula recommended by (Ogunrinade and Ogunrinade, 1980) as EL = SSrx* Coy* Roz (Tables 2 and 3; Figures 5 and 6).

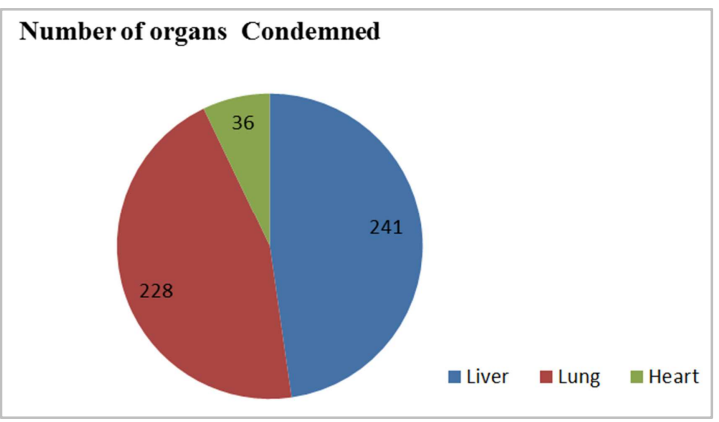

Figure 5. Total number of organ rejection in Adama municipal abattoir during the study period $(N=384)$.

Table 2. Rejection rate of each organ.

\begin{tabular}{llll}
\hline Organs & Total No. of organs examined & Total No. of organs condemned & Organs rejection rate \\
\hline Liver & 384 & 241 & 0.63 \\
Lung & 384 & 228 & 0.59 \\
Heart & 384 & 36 & 0.09 \\
\hline
\end{tabular}

Table 3. Rejection rates, price and annual financial loss of condemned organs.

\begin{tabular}{llllll}
\hline Types of organ & $\begin{array}{l}\text { Total No. organs } \\
\text { Condemnation }\end{array}$ & $\begin{array}{l}\text { The rejection rate of } \\
\text { organs }\end{array}$ & $\begin{array}{l}\text { The average price of organs } \\
\text { at the local market (ETB) }\end{array}$ & $\begin{array}{l}\text { Annual } \\
\text { slaughter rate }\end{array}$ & $\begin{array}{l}\text { Annual loss } \\
\text { estimation (ETB) }\end{array}$ \\
\hline Liver & 241 & 0.63 & 100 & 45,625 & $2,874,375$ \\
Lung & 228 & 0.59 & 20 & 45,625 & 538,375 \\
Heart & 0.09 & 30 & 45,625 & $123,187.50$ \\
Total estimated loss (ETB) & 36 & & & $3,535937.50$ \\
\hline
\end{tabular}

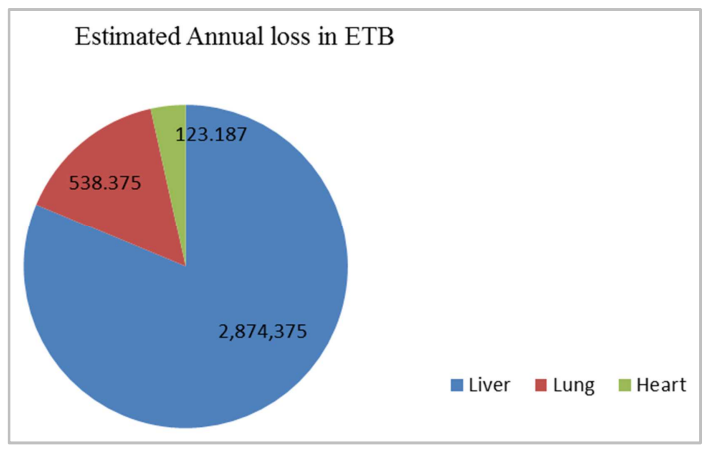

Figure 6. Estimated annual loss in Adama municipal abattoir with 45,625 annual slaughter capacity.

\section{Discussion}

Meat inspection is conducted in the abattoir for the purpose of screening and removing animals with abnormal pathological lesions unsafe for human consumption and having poor aesthetic value. An important function of meat inspection is to assist in monitoring diseases in the national herd and flock by providing feedback information to the veterinary service to control or eradicate disease and to produce wholesome products and to protect the public from zoonotic hazards [15].

The current study revealed that fasciolosis, hydatidosis, cirrhosis, calcification, pneumonia, emphysema, abscessation, and Pericarditis were the causes of liver, lung, and heart condemnation in cattle slaughtered at Adama municipal abattoir. The rejection rate of organs recorded in this study was $62.76 \%, 59.37 \%$, and $9.37 \%$ for the liver, lungs, and heart respectively. Interestingly, the finding of the rate of liver condemnation in this study was comparable with the value reported by Nurit [32] from Kombolcha and Amene [5] from Jimma municipal abattoir who reported $66.55 \%$ and $64.4 \%$ respectively but higher than a report from Gondar ELFORA abattoir by Denberga et al. [31].

Fasciolosis has been reported to be one of the major disease problems of the livestock industry. Many pieces of research have been conducted by different authors of different countries indicated the wide distribution of the disease with its prevalence reaching up to $84 \%$. In the current study, $30.46 \%$ of the animals' liver abnormalities were found to be caused by fasciolosis. However, this result was remarkably lower than reports of Tadelle and Worku [27], and Berhe et al., [6] from Jimma and Mekelle municipal 
abattoirs, respectively. Amazingly, the result reported from Kafue, Zambia by Phiri [24] showed a slightly higher percentage than the current finding. Although, the results obtained are surprisingly higher than the value reported by Okoli et al., [23] and Kithuka et al., [19] from Nigeria and Kenya, respectively. These differences can be attributed to the difference in the agro-ecological conditions and strategic control of internal parasites in the areas.

In this study, lungs condemned were $59.37 \%$ of the total lungs inspected due to hydatid cyst, pneumonia, emphysema, abscess, and hepatization. From the total lung rejected, hydatid cyst accounts about $32.9 \%$ as principal causes of lung condemnation followed by pneumonia with $11.72 \%$. This finding is lower than reported by Jobre et al., [17] and Getachew et al., [14] from Bishoftu and Adama, respectively. Contrary to this, the finding is higher than finding reported by Abunna et al., [2] from Wolaita Sodo and Genet et al., [13] from Gondar. Similar to this study other studies reported that the liver and lungs to be the most commonly affected organs by hydatid cyst [17]. This is because of lung and liver contain the highest capillary bed in the body [15].

Pneumonia is the second important disease for the cause of lung condemnation in the study abattoir. The prevalence of pneumonia was recorded as $11.72 \%$. This finding is higher than the rejected rate $(8.8 \%)$ that was reported by Raji et al., [25] in cattle slaughtered at Zaria and $(0.14 \%)$ in cattle slaughtered at Zango abattoir, Nigeria [8]. A number of factors may explain the high prevalence of pneumonic lungs, including stress factors such as exposure to dust from the environment or exhaustion during long treks of pastoral livestock in search of pasture and water and when animals are taken to livestock market or abattoirs and parasitism.

The rejection rate of heart was not as significant as those liver and lung and as such unlikely to produce the pronounced economic effects associated with the first two. The other causes of condemnation in all organs were less frequent and most associated with unspecific pathogenic conditions.

The total financial loss calculated in this study, due to condemnation of liver, lung, and heart, was 3,535,937.50 ETB or $153,736.41$ USD per year. The financial loss encountered in this study is higher than previous studies 4,674.2 USD from Adawa Municipal Abattoir [18]; 6,300 USD from Jimma abattoir [28] and 4000 USD from Wolaita Sodo abattoir [2]. The difference in the financial loss estimated in various abattoir and/or parts of Ethiopia would be due to the variations in the prevalence of the disease, mean the annual number of cattle slaughtered in the different abattoirs and also the variation in the retail market price of organs.

\section{Conclusion}

The objective of this study was to identify the major reasons for organ condemnation in cattle slaughtered at Adama municipal abattoir and to compute the annual financial loss as a consequence of organ condemnation. From the research that has been conducted, it is possible to conclude that fasciolosis and hydatidosis are the most important factors of liver and lung condemnation, respectively. From this investigation, the annual financial loss of liver condemnation is estimated to be $2,874,375 \mathrm{ETB}$ and that of lung condemnation is 538,375 ETB. This research was concerned with the rejection rate of liver, lung, and heart. Further research with the inclusion of causes of condemnation of other visceral organs has to be conducted as this provides the full insight of financial loss that the country is losing.

\section{Recommendations}

a) Awareness creation to the animal owners about an animal husbandry management system

b) Animal health control measures like deworming should be implemented routinely

c) Policymakers should be incorporate this impact into their strategy to shape country-based saving of financial loss

d) Regular antemortem and postmortem inspection should be regularly conducted across country's municipal abattoirs

\section{Authors' Contributions}

MA and TG designed and conducted the research work. Data were analysed and the manuscript was written by BK and MA. All the authors have read and approved the final manuscript.

\section{Acknowledgements}

We thank Adama Municipal abattoir for their permission to do this study.

\section{Competing Interests}

The authors declare that they have no competing interests.

\section{References}

[1] Abebe, G. 1995. Current status of veterinary education and health research in Ethiopia in Veterinary Medicine impact on health and nutrition in Africa. Proceeding of an international conference, Addis Ababa. Pp. 133-138.

[2] Abunna F., Asfaw L., Megersa B., Regassa A. 2010. Bovine fasciolosis: Coprological, abattoir survey and its economic impact due to liver condemnation at Sodo Municipal Abattoir, Southern Ethiopia. Tropical Animal Health and Production, 42: 289-292.

[3] Alembrhan A., Haylegebriel T. 2013. Major causes of organ condemnation and economic loss in cattle slaughtered at Adigrat municipal abattoir, northern Ethiopia. Vet. World. 6: 734-738.

[4] Alton G., Lpeah D., Bateman, K., Mc Nab W. Berk, O. 2010. Factors associated with whole condemnation rates in provincially inspected abattoir in Ontario 2001-2007: Implication for food animal syndromic surveillance. BMC Vet. Res. 6: 42. 
[5] Amene, F., Eskindir, L. and Dawit, T. 2012. Cause, Rate and Economic Implication of Organ Condemnation of Cattle Slaughered at Jimma Municipal Abattoir, South-western Ethiopia. Global Veterinarian, 9: 396-400.

[6] Berhe, G., Berhane K. and G. Tadesse, 2009. Prevalence and economic significance of Fasciolosis in cattle in Mekelle area of Ethiopia. Tropical Animal Health and Production, 41: $1503-1504$

[7] Chabra M. B., Singla L. D. 2009. Food-borne parasitic zoonoses in India: Review of recent reports of human infections. Journal of Veterinary Parasitology 23 (2): 103-110.

[8] Clement, B. J., I. J. Alawa and B. L. Joseph, 2010. Six years survey of pathological conditions of slaughtered animals at Zango abattoir in Zaria, Kuduna state, Nigeria. Tropical Animal Health and production, 43: 127-131.

[9] CSA, 2010: Federal Democratic Republic of Ethiopia. Central Statistical Authority, Agricultural Sample Enumeration, Ethiopia.

[10] CSA, 2013. Agricultural Sample Survey, Volume II. Report on Livestock and Livestock Characteristics, Addis Ababa, Ethiopia, Pp: 1-10.

[11] Food and Agriculture Organization, 1994. Manual of meat inspection for developing countries. FAO. countries. FAO. Production and Health, Pp: 119-359.

[12] Food and Agriculture Organization, FAO. 2007. Manual on meat inspection for developing Countries. Animal and health production papers Food and Agriculture organization of the United Nations: Edited by: Dr. Bedru Hussen, Mekele University, February 2007, Mekele, Ethiopia.

[13] Genet M, Tadesse G, Basaznew B, Mersha C. 2012. Pathological Conditions Causing Organ and Carcass Condemnation and Their Financial Losses in Cattle Slaughtered in Gondar, Northwest Ethiopia. African Journal Basic Applied Science, 4: 200-208.

[14] Getachew, E. W. 2008. Major diseases of export orienated livestock in export Abattoir in and around Ada'aliben Woreda, DebereZeit, Faculty of Veterinary Medicine and Haramaya University, Ethiopia. DVM Thesis.

[15] Gracey, I. F., Collins, O. S. Huey, R. J. 1999. Meat hygiene, $10^{\text {th }}$ ed. London: Bailliero tindall, Pp: 223-260.

[16] Jatenie J, Mahendra P, Rahman T. 2014. Investigation into major causes of organs condemnation in bovine slaughtered at Adama municipal abattoir and their economic importance. Haryana. Veterinary. 53: 139-143.

[17] Jobre, Y., Lobago, R. Tiruneh, G. Abebe and P. H. Dorchies, 1996. Hydatidosis in three selected regions of Ethiopia: An assessment trial on its prevalence, economic and public health importance, Review on Veterinary Medicine, 147: 797-804.

[18] Kele, M., H. Tesfaye and Y. Getachew, 2010. Bovine fasciolosis: Prevalence and its economic loss due to liver condemnation at Adwa Municipal Abattoir, North Ethiopia. Ethiopian applied Sciences, 1: 39-47.
[19] Kithuka, J. M., N. Maingi and F. M. Njeruh, 2002. The prevalence and economic importance of bovine Fasciolosis in Kenya: an analysis of abattoir data, Ondestepoort, Journal of Veterinary Research, 69: 255-62.

[20] Mellau, L. S, Longa H. E, Karimuribu E. D. 2010. A Slaughter house survey of liver lesion in slaughter cattle, sheep and goats at Arusha, Tanzania.

[21] Mezegebu, Y. 2003. Major cause of organ condemnation in ruminants slaughtered at Gonder Abattoir, North Western Ethiopia. DVM thesis, Faculty of Veterinary Medicine, Addis Ababa University, Debre-Zeit, Ethiopia.

[22] MOA, 2004. Budgeting \& planning reports, summery of MOA, North Gondar zone, 1987-1988.

[23] Okoli, I. C., E. C. Agoh, G. C. Okoli, G. C Idemi and D. O. Umesiobi, 2000. Bovine and Caprine Fasciolosis in Enugu State of Nigeria: Retrospective analysis of abattoir records (1983- 1997) and six-month prevalence study. Bulletin of Animal Health and production for Africa, 48: 7-11.

[24] Phiri A. M., 2006. Common conditions leading to cattle carcasses and offal condemnations at three abattoirs in western province of Zambia and their zoonotic implications to consumers, Journal of South African Veterinary Association, 77: $28-32$.

[25] Raji, M. A., S. O. Salami and J. A. Ameh, 2010. Pathological condition and lesions observed in slaughtered cattle at Zaria abattoir. Journal of Clinical Pathology and Forensic Medicine, 1: 9-12.

[26] Sariözkan, S. and Yalcin, C. 2009. Estimating the production losses due to cystic echinococcosis in ruminants in Turkey. Veterinary Parasitology, 163: 330-334.

[27] Tadelle, T. and T. Worku, 2007. The prevalence and economic significance of bovine Fasciolosis at Jimma, Abattoir, Ethiopia, The Internet Journal of Veterinary Medicine, 3: 15-16.

[28] Tolesa, T. and W. Tigre, 2007. The prevalence and economic significance of bovine fasciolosis at Jimma abattoir, Ethiopia. College of agriculture and Veterinary Medicine, Jimma University.

[29] Thrusfield, M., 2005. Determinants of disease. Veterinary epidemiology, 3 ed. Blackwell publishing, pp: 345-543.

[30] Ogunrinade A. and Ogunrinade B. I., 1980. Economic importance of bovine Fasciolosis in Nigeria. Trop Animal Health Production. 12: 155-160.

[31] Denberga et al., 2011. Major causes of organ condemnation and financial significance of cattle slaughtered at Gondar Elfora Abattoir, Northern Ethiopia. Global Veterinaria Journal. 7 (5): 487-490.

[32] Nurit M., Zerihun H. and Serkalem M., 2012. Major cause of Liver condemnation and associated Financial Loss at Kombolcha Elfora Abattoir, South Wollo, Ethiopia. European Journal of Applied Sciences. 4 (4): 140-145. 